\title{
PARENT-CHILD RELATIONSHIPS AND SEXUAL IDENTITY IN MALE AND FEMALE HOMOSEXUALS AND HETEROSEXUALS
}

\author{
NORMAN L. THOMPSON, JR. ${ }^{1}$ \\ University of Pennsylvania
}

\author{
DAVID M. SCHWARTZ, BOYD R. MCCANDLESS,
} AND DAVID A. EDWARDS

Emory University

\begin{abstract}
This article includes two studies of reported parent-child relations and sexual identity: one of a population of 84 white, well-educated female homosexuals and their 94 matched heterosexual controls and the other of a group of 127 similarly welleducated, white male homosexuals and their 123 heterosexual matched controls. Female homosexuals reported having had more negative relations with their fathers in childhood that female heterosexuals, although a wide variety of parent-daughter relations was reported by both groups. The female homosexuals were neither mother nor father identified, but they were more distant from both parents and other people than their controls. The female homosexuals also reported a more masculine childhood than the heterosexuals, and they were more masculine on an objective measure of masculinity-femininity. Compared with their controls, the male homosexuals reported more close-binding, intimate mothers and hostile, detached fathers than the heterosexual controls. As with the two female groups, a wide variety of parentson relations was reported. Homosexual males were not more mother identified than their controls, but, like the female group, they were more distant from parents and other people than the matched controls. Male homosexuals reported more feminine childhoods, and they were less masculine than controls on a masculinity-femininity test.
\end{abstract}

Considerable attention has been focused on the psychological factors involved in homosexuality. Today, most students in the area realize that a homosexual adjustment has exceptionally complex determining components, but they agree that one profitable approach is the study of the relationship between parents and the prehomosexual child, especially as this affects the child's sex-role identification.

Few research workers have studied female homosexuality. Thus, little is known about parent-child interactions among prehomosexual females and the relations of these interactions with later sexual identity; and the little research that has been conducted is inconsistent in its results.

Looking at homosexuals in Britain, Bene (1965) found no differences between female homosexuals and the heterosexual controls in their reported feelings toward their mothers. In contrast, Gundlach and Riess (1968) found that homosexual females more often reported feeling neglected and ignored by their mothers,

1 Requests for reprints should be sent to Norman L. Thompson, Jr., Graduate School of Education, University of Pennsylvania, Philadelphia, Pennsylvania 19104. who had treated the daughters impersonally and, in many instances, without love.

The fathers of the homosexual females are more consistently seen in an unfavorable manner. Bene's (1965) homosexual $S$ s were more hostile toward and afraid of their fathers than the heterosexual females. The homosexuals also saw their fathers as weak individuals. Gundlach and Reiss (1968) found that lesbians reported their fathers as less warm and affectionate and more indifferent, acting like strangers toward their daughters.

In a study of females in extended psychoanalysis, Kaye et al. (1967) found no differences between homosexuals and heterosexuals in their early relationships with their mothers. Findings from this study, in which the data were supplied by the therapist, indicated a negative relationship of homosexuals with their fathers. The father of the lesbian was seen as a superficially feared and puritanical person who was overly possessive of his daughter. In addition, he was seen as attempting to discourage her development as a female.

Results from these studies suggest that the father may be centrally involved in the early interpersonal dynamics of the prehomosexual girl. The role of the mother is much less clear. 
Certainly, much more systematic research must be done in this area, using a more diverse group of lesbians than those who, for the most part, were members of a homophile organization (Bene, 1965; Gundlach \& Reiss, 1968) or in psychoanalysis (Kaye et al., 1967).

In studies of family backgrounds among males, Bieber et al. (1962) and Evans (1969) found that more homosexuals than controls had a mother who was close binding and intimate with her son and minimizing toward her husband. The typical father of homosexuals was detached and hostile in his relations to his son. This is considered the "classical" pattern. Likewise, Bene (1965) found that compared with her controls, more of the male homosexuals were hostile toward their fathers and saw their fathers as weak. However, Bene found no differences between experimentals and controls in their perception of their mothers. Apperson and McAdoo (1968) also found that the reported relationship between male homosexuals and their fathers was quite negative.

Responsibility for appropriate sexual identification in males is thought to rest most heavily on the father (McCandless, 1970). Evidence for this is relatively clear (Biller, 1970; Biller \& Borstelmann, 1967). Therefore, based on the findings of Bieber et al. (1962), Bene (1965), Apperson and McAdoo (1968), and Evans (1969), it appears that homosexual males should exhibit a greater degree of inappropriate sex-role identification than heterosexual males. Moreover, the more closely the parental relationships for any male approximates the "classical" pattern, the more inappropriate is his sex-role identification.

Chang and Block (1960) supplied evidence that supports the notion that male homosexuals have inappropriate identifications. They compared a group of adequately functioning male homosexuals with controls on a measure of parent identification. The homosexual group checked more of the same adjectives than the control group when asked to describe "yourself" and "your mother" and fewer of the same adjectives when asked to describe themselves and their fathers. Chang and Block concluded that these homosexuals more strongly identified with their mothers and more strongly disidentified with their fathers than the controls.
Authors of the previously mentioned studies have either explored parental factors or some aspect of sexual identity without looking directly at the relationship between the two. The present studies are further investigations of the reported parent-child interactions among adequately functioning female and male homosexuals (Thompson, McCandless, \& Strickland, 1971) and heterosexuals, and the relationship between these early interactions and sexual identity.

\section{Subjects}

\section{Method}

The homosexual $S$ s were volunteers who were recruited through their friends. The friends ("tester") distributed the test packets that were eventually returned anonymously to the first author. Most of the $S$ s lived in Atlanta, but approximately one-third were from other eastern states. Heterosexual controls were recruited in the same manner, with almost half obtained by the same individuals who tested the homosexual $S$ s. These heterosexual controls were from about the same geographical distribution, although more of them came from universities in the Atlanta area.

A homosexual was defined as one who perceived himself as homosexual and was known to one of the testers as a homosexual. A heterosexual was defined as any individual not known to a tester as a homosexual. Three male control $S$ s originally tested as heterosexuals identified themselves as bisexual or predominantly homosexual in feelings, and were dropped from the study. However, heterosexual Ss who admitted to some homosexual experience and/or feelings (15\% of the female and $22 \%$ of the male control group) but who stated that they were predominantly heterosexual in sexual feelings were kept in the sample.

In a study of this type, it is not possible to speak rigorously of refusals since one does not know whether failures to return test packets were a function of the testers or the $S$ s. However, in an anecdotal sense, the authors know of only three refusals from male homosexuals, each coming from a legally married man. There were many more refusals from female homosexuals, including sabotage of test packets that had been gathered in a group situation. In order of difficulty in filling out the samples, easiest were the female controls, the male homosexuals, the male controls, and the female homosexuals.

All $S$ s were American born and white. Homosexual and heterosexual $S$ s ( 84 female homosexuals, 94 female controls, 127 male homosexuals, 123 male controls) were matched for age, sex, and education. Demographic data are given in Table 1 . As can be seen, the $S$ s were young, well educated, and predominantly Protestant in religion.

\section{Instruments}

Parent-child interactions. The items adapted by Evans (1969) from the Bieber et al. (1962) study were 
TABLE 1

Age, Education, Marital Status, and Rejugion

\begin{tabular}{|c|c|c|c|c|}
\hline Variable & $\begin{array}{l}\text { Female homo- } \\
\text { sexuals }(n=84)\end{array}$ & $\begin{array}{l}\text { Female hetero- } \\
\text { sexuals }(n=94)\end{array}$ & $\begin{array}{l}\text { Male homosexuals } \\
\qquad(n=127)\end{array}$ & $\begin{array}{c}\text { Male hetero- } \\
\text { sexuals }(n=113)\end{array}$ \\
\hline \multicolumn{5}{|l|}{ Age (in years) } \\
\hline Range & $17-48$ & $18-48$ & $18-51$ & $17-54$ \\
\hline$M$ & 28.60 & 26.99 & 28.06 & 27.43 \\
\hline$S D$ & 6.04 & 6.21 & 7.11 & 8.27 \\
\hline \multicolumn{5}{|l|}{ Education (in years) } \\
\hline Range & $9-21$ & $12-20$ & $11-28$ & $11-24$ \\
\hline$M$ & 15.68 & 15.63 & 16.06 & 16.56 \\
\hline$S D$ & 2.48 & 1.97 & 2.69 & 2.81 \\
\hline \multicolumn{5}{|l|}{ Marital staus (in $\%$ ) } \\
\hline Single & 75.0 & 32.9 & 91.3 & 43.1 \\
\hline Married & 4.8 & 60.6 & 3.2 & 52.0 \\
\hline Divorced or separated & 19.0 & 2.1 & 5.5 & 3.3 \\
\hline Divorced remarried & 1.3 & 3.2 & .0 & 1.6 \\
\hline Widowed & .0 & 1.1 & .0 & .0 \\
\hline \multicolumn{5}{|l|}{ Religion (in \%) } \\
\hline Protestant & 54.8 & 68.1 & 56.7 & 60.2 \\
\hline Roman Catholic & 11.9 & 8.5 & 11.0 & 8.1 \\
\hline Jewish & 2.4 & 12.9 & 4.7 & 11.4 \\
\hline Orthodox & .0 & 2.1 & .8 & .0 \\
\hline Other & 1.2 & .0 & .0 & .0 \\
\hline None & 29.7 & 8.5 & 26.8 & 19.5 \\
\hline
\end{tabular}

used to measure parent-child interactions. Several of the Evans items refer only to either mother-child or father-child interactions. Each of these questions was repeated to measure the individual's interactions with the parent of the opposite sex. Therefore, there were 46 items in all, 7 relating to development, 38 pertaining to parent-child interactions, and 1 question regarding the $S$ 's physical make-up in childhood. In all, 25 (14\% of the female and $12.8 \%$ of the male) $S$ s failed to answer one or more of the questions, while 10 females and 5 males omitted three or more. There were no homosexual-control differences here. No $S_{\mathrm{s}}$ were dropped from the study due to the omission of items on the questionnaire.

Sexual identity. Three different instruments were used to measure sexual identity. The first of these was the semantic differential. This measure was employed to assist the individual's perceived parental similarity and perceived sex-role similarity. Osgood, Suci, and Tannenbaum (1957) posited a three-dimensional semantic space composed of the evaluative, potency, and activity dimensions found through factor analysis. The meaning of a concept is learned through an individual's experience and thus lies at some point in the semantic space on these three dimensions. Two concepts lying near each other in the semantic space are assumed to have similar meanings. Therefore, if the meanings of the concepts "myself" and "my father" are similar and "myself" and "my mother" are dissimilar, it is assumed that this individual perceives himself as similar to his father. Lazowick (1955) and Dignan (1965) have found the semantic differential to be a useful measure of perceived similarity.
The nine concepts and nine scales in the present study were those used by Lazowick (1955) and Dignan (1965). The degree of perceived similarity was defined in terms of the $D$ score described by Osgood, et al. (1957). $D$ is the difference in the scale positions for each concept as rated by the $S$ (e.g., myself/man), squared, summed, and the square root taken. The larger the $D$ score, the further apart the concepts are in meaning.

The Adjective Check List Masculinity-lemininity scale (Heilbrun, 1968) was used as an objective measure of sexual identity. Each masculine adjective checked was given a score of 1 . Feminine adjectives were each scored as -1 . The total possible masculinity-femininity scores on the Adjective Check List ranged from 28 to -25 .

The third measure of sexual identity was the Franck Drawing Completion Test (Franck \& Rosen, 1949). 'This projective instrument, which has differentiated between males and females in all societies in which it has been used, has been scored reliably and validated in a number of studies (Cottle, Edward, \& Pleck, 1970; Lipsitt \& Strodtbeck, 1967; Miller \& Swanson, 1960).

Eleven of the 36 Franck test stimuli were found to discriminate best between males and females by Strodtbeck, Bezdek, and Goldhammer (1970). In the present study, responses to these 11 test stimuli were scored by two psychology graduate students trained in scoring according to the criteria set forth by Bezdek and Madsen (1970). A score of 1 was given if a drawing corresponded to a masculine criterion response. Feminine drawings were scored as 0 . The maximum possible score was 11 . Using the training manual, the two scorers attained a reliability of .90 and .95 , respectively. They 
graded all protocols for both the female and the male studies without knowledge of the sex or sex orientation of the $S \mathrm{~s}$. The reliability between the two scores, based on 200 protocols selected at random from the two studies, was .93 .

\section{RESULTS}

From the 46-item Parent-Child Interactions Questionnaire, 30 items distinguished between the female homosexual and heterosexual groups at the .05 level or less, of which 7 were at the .001 level or less. ${ }^{2}$ The seven best discriminators, from first to seventh, were: (a) played baseball (more homosexuals often or very often; more heterosexuals sometimes); (b) physical makeup as a child (more homosexuals athletic, more heterosexuals coordinated); (c) played with girls before adolescence (more homosexuals sometimes; more heterosexuals often or always); (d) avoided physical fights (more homosexuals sometimes or never; more heterosexuals always or often); (e) accepted father (more homosexuals moderately through no; more heterosexuals strongly); $(f)$ felt accepted by mother (more homosexuals moderately through not at all; more heterosexuals strongly); and ( $g$ ) father openly preferred child to mother (more homosexuals always and often; more heterosexuals seldom or never).

These seven most significant chi-square differences clearly provide the flavor of the developmental and parent-child questionnaire results for the female samples.

For the male samples, the same 46-item questionnaire yielded 32 chi-squares significant at the .05 level or less, 27 of them being at the .001 level or less. The seven most discriminating items in order from the highest were: $(a)$ played baseball (note that this was also the most discriminating item for the women, with homosexuals concentrating on never or sometimes; heterosexuals, often or very often); (b) played competitive group games (homosexuals, never or sometimes; heterosexuals, often or very often) ; (c) child spent time with father (homosexuals, very little; heterosexuals, considerable and a great deal $) ;(d)$ physical makeup as a child (homosexuals, frail, clumsy, or coordinated;

\footnotetext{
${ }^{2}$ Copies of the Parent-Child Interactions Questionnaire and the full data table including results from its administration to all four groups may be obtained from the senior author on request.
}

heterosexuals, athletic); (e) felt accepted by father (homosexuals, mildly or no; heterosexuals, stron:ly); $(f)$ played with boys before adolescence (homosexuals, sometimes; heterosexuals often or always); and ( $g$ ) mother insisted on being center of child's attention (homosexuals, often or always; heterosexuals, never or seldom).

The other items significant for males at the .001 level or less, all in the predictable direction, were: fearful of physical injury as a child; avoided physical fights; played with girls before adolescence; parents share similar interests; mother "seductive" toward child; mother discouraged masculine attitudes/activities; mother's relationships with father/other men (homosexuals, frigid or cold; heterosexuals, warm); mother allied with child against father; mother openly preferred child to father; child was mother's confidant; child was mother's favorite; mother encouraged masculine attitudes/activities; aware of hating father as a child; afraid father might physically harm the child; accepted father; and respected father.

The pattern that emerged for females is one of tomboyishness and feelings of maternal rejection and father overacceptance with, at the same time, rejection of the father. The classic pattern of feminine play interests, doubts of (or a feeling of "grace" about) own body, mother seduction, feelings of rejection by father, and rejection of father emerged clearly for the male homosexual group.

Only 7 of the 46 items discriminated for neither sex. They were: mother and father spent time together; mother considered puritanical; aware of hating mother as a child; afraid mother might physically harm the child; father insisted on being center of attention; father discouraged masculine attitudes/activities; and father considered puritanical.

In order to obtain a clearer picture of the background patterns of the various groups and to be able to relate them to the measures of sexual identity, the items from the ParentChild Interactions Questionnaire were combined into three scales similar to those used by Evans (1969). These three scales (Developmental, Mother, Father) were composed of the items that Evans used, with the exception of the physical make-up questions. This question was omitted from the Developmental 
TABLE 2

Means and Standard Deviations for the Ss for Mother, Father, and Developmental Scales from the Parent-Child Interactions Questionnatre

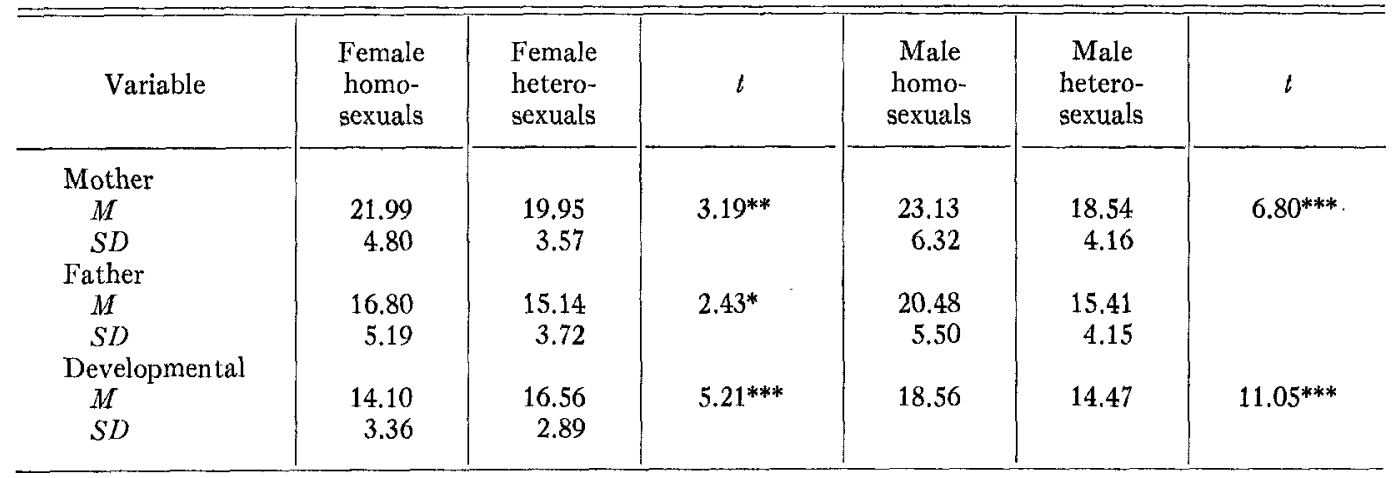

$* p<.05$

$\begin{array}{rl}* * & p<.01 \\ * * * & p<.001\end{array}$

scale used in the present study, and the question concerning playing with boys as a child that was included in the present Developmental scale was not a part of the Evans scale.

A score was obtained for each $S$ by weighting each item from 1 to 4 points, with the higher weighting in the direction of the "classical" male homosexual pattern (Bieber et al., 1962). Any item omitted by an $S$ was given a neutral score of 2.5. The total possible score was 40 for the mother scale, 32 for the father scale, and 28 for the developmental scale. We realize that this scale may be more suitable for the male than the female sample, but since this is an exploratory study for females, it seems profitable to employ the same measures. Additionally, the work of Bene (1965), Kaye et al. (1967), and Gundlach and Riess (1968) with female homosexuals suggested that their backgrounds may be similar to those of male homosexuals as far as father-child relations are concerned.

The results for these three scales are given in Table 2. As a group, the female homosexuals are more similar than the heterosexual control $S$ s to the "classical" male homosexual pattern in relation to their parents. In this pattern, the mother is close binding and intimate with her child and dominant and minimizing toward her husband. The father is detached and hostile to the child. However, the lesbian is not similar to the "classical" male pattern in that the male homosexual describes himself as a lone wolf in childhood who played with girls, someone who was fearful of physical injuries and fights, and a nonparticipant in competitive games. The lesbian only fits this pattern in that she describes herself as a lone wolf.

\section{Measures of Sexual Identity}

Perceived similarity. Several measures of sexual identity were given in order to look at the $S$ s' present sexual identity. One of these was the semantic differential, which was used as a measure of perceived parental and sex-role similarity. The means and standard deviations

TABLE 3

Means and Standard Deviations for the $S S$ For Perceived Parental Role Similarity and PerCeived Sex-Role Similarity

\begin{tabular}{|c|c|c|c|c|c|c|}
\hline $\begin{array}{l}\text { Vari- } \\
\text { able }\end{array}$ & $\begin{array}{l}\text { Female } \\
\text { homo- } \\
\text { sexuals }\end{array}$ & $\begin{array}{l}\text { Female } \\
\text { hetero- } \\
\text { sexuals }\end{array}$ & $t$ & $\begin{array}{l}\text { Male } \\
\text { homo- } \\
\text { sexuals }\end{array}$ & $\begin{array}{c}\text { Male } \\
\text { hetero- } \\
\text { sexuals }\end{array}$ & $t$ \\
\hline $\begin{array}{c}\text { Mother } \\
M \\
S D \\
\text { Father }\end{array}$ & $\begin{array}{l}4.90 \\
2.70\end{array}$ & $\begin{array}{l}4.52 \\
2.02\end{array}$ & $3.82^{* * * * *}$ & $\begin{array}{l}5.71 \\
2.28\end{array}$ & $\begin{array}{l}5.08 \\
1.79\end{array}$ & $2.44^{*}$ \\
\hline$\underset{\text { Woman }}{M}$ & $\begin{array}{l}6.28 \\
2.97\end{array}$ & $\begin{array}{l}5.25 \\
1.97\end{array}$ & $2.69 * *$ & $\begin{array}{l}6.15 \\
2.53\end{array}$ & $\begin{array}{l}4.45 \\
2.00\end{array}$ & $5.90 * * *$ \\
\hline $\begin{array}{c}M \\
M \\
S D \\
\text { Man }\end{array}$ & $\begin{array}{l}4.80 \\
2.11\end{array}$ & $\begin{array}{l}4.05 \\
1.76\end{array}$ & $2.56 *$ & $\begin{array}{l}5.97 \\
2.55\end{array}$ & $\begin{array}{l}4.97 \\
1.71\end{array}$ & $3.65^{* * * *}$ \\
\hline $\begin{array}{l}M \\
S D\end{array}$ & $\begin{array}{l}5.94 \\
2.49\end{array}$ & $\begin{array}{l}5.09 \\
2.26\end{array}$ & $2.37 *$ & $\begin{array}{l}5.14 \\
2.56\end{array}$ & $\begin{array}{l}4.15 \\
1.85\end{array}$ & 3.51 **** \\
\hline
\end{tabular}

Note. High scores are less similar to the concept. $* p<.05$.

$\begin{array}{rl}* * & p<.01 \\ * * * & 0.001\end{array}$ 
of these measures are given in Table 3 . They are expressed in terms of $D$ scores (distance scores), so that the higher the score, the less similar the individual perceives herself or himself to that particular parent or sex role.

From Table 3, we can see that both female and male homosexuals are more distant from both parents, as well as from males and females in general, than are heterosexuals. In contrast the results of Chang and Block (1960), who used a different measure of closeness to parent, the male homosexuals here did not see themselves as closer to one parent than to another $(t=1.49, \quad d f=252)$ nor did the female homosexuals $(l=.36, d f=166)$. As expected, heterosexual females perceived themselves as closer to their mothers than their fathers $(t=2.51, d f=186, p<.05)$; and the heterosexual males perceived themselves as closer to their fathers than their mothers $(t=2.60$, df $=244, p<.01$ ).

While both homosexual groups saw themselves as more distant from both sex roles than was true for the heterosexuals, homosexual and heterosexual females saw themselves closer to the female than the male role, and both groups of males saw themselves closer to the male than the female role (all $t \mathrm{~s}<.01$ ).

The picture that emerges for both homosexual males and females, then, is one of distance, perhaps alienation, from people in general. These females and males see themselves as equally distant from both their mothers and fathers. They perceive themselves to be closer to their biological sex in general than to the opposite sex. However, they are more distant from both than the same-sexed heterosexual groups.

Correlations between the Mother, Father, and Developmental scales from the ParentChild Interactions Questionnaire and the perceived similarity scores are given in Table 4. Interestingly, there were no significant relationships among these variables for female heterosexuals. Female homosexuals who scored high on the Mother scale (assumed to indicate a close binding, intimate mother) were more distant from men in general. Homosexual females who were high on the Father scale (presumably a hostile, detached father) were more distant from the concepts of father, women, and men. Lesbians who scored high on the Develop-
TABLE 4

Correlations betweten the Mother, Father, and Developmental Scales from the Parent-Chrld Interactions Questionnaire and Perceived SIMILARITY

\begin{tabular}{|c|c|c|c|c|}
\hline Variable & $\begin{array}{l}\text { Female } \\
\text { homo- } \\
\text { sexuals }\end{array}$ & $\begin{array}{l}\text { Female } \\
\text { hetero- } \\
\text { sexuals }\end{array}$ & $\begin{array}{c}\text { Male } \\
\text { homo- } \\
\text { sexuals }\end{array}$ & $\begin{array}{l}\text { Male } \\
\text { hetero- } \\
\text { sexuals }\end{array}$ \\
\hline $\begin{array}{l}\text { Mother scale with } \\
\text { Mother } D \\
\text { Father } D \\
\text { Woman } D \\
\text { Man } D \\
\text { Father scale with } \\
\text { Mother } D \\
\text { Father } D \\
\text { Woman } D \\
\text { Man } D \\
\text { Developmental scale } \\
\text { with } \\
\text { Mother } D \\
\text { Father } D \\
\text { Woman } D \\
\text { Man } D\end{array}$ & $\begin{array}{l}.04 \\
.16 \\
.01 \\
.22^{*} \\
.11 \\
.41^{* * * * *} \\
.25^{*} \\
.34^{* *}\end{array}$ & $\begin{array}{r}.14 \\
.09 \\
-.12 \\
-.03\end{array}$ & $\begin{array}{l}.23^{* * k} \\
.40^{* * k * k} \\
.05 \\
.19^{*}\end{array}$ & $\begin{array}{l}.04 \\
.25 * * \\
-.05 \\
.23 *\end{array}$ \\
\hline
\end{tabular}

$* p<.05$.

$* * * p<.01$
$* * * *$
$* * 001$

mental scale (indicative of a passive, feminine, lone-wolf woman) saw themselves as more distant from both parents and males in general.

For the male groups, both homosexuals and heterosexuals who scored high on the Mother scale were more distant from their fathers, and such heterosexuals were also distant from their mothers.

Homosexual and heterosexual males who scored high on the Father scale were more distant from their fathers, and the heterosexuals were also more distant from their mothers and from males in general. Although none of the correlations was very high, it is interesting that a reported negative relationship with either parent is related to perceiving the father as dissimilar from oneself for both groups of males.

Both male homosexuals and heterosexuals who did not engage in activities considered masculine in childhood were more distant from both their fathers and males in general. If this distance indicated alienation, such a relationship is reasonable given the American approval (especially by fathers) of boys who engage in competitive sports, with a resulting isolation of boys who do not.

Adjective Check List. The Adjective Check List Masculinity-Femininity scale was used as an objective measure of sexual identity. The female homosexuals scored more masculine 
than the heterosexuals (at $<.01$ ), and the male heterosexuals as more masculine than the homosexuals (at $<.05$ ). Correlations of Adjective Check List scores with other measures employed in these studies followed no consistent pattern, and were generally so low as not to be useful in predictive context.

Franck Drawing Completion Test. The Franck Drawing Completion Test was used as a projective measure of sexual identity. A score of 0 is most feminine, a score of 11 is most masculine. There was no significant difference $(t=1.42$, df $=176)$ between the female homosexuals' mean of 5.79 and the female heterosexuals' mean of 5.36. Male homosexuals scored 5.78, male heterosexuals 5.63. $t$ for this difference was nonsignificant. The Franck test was not related to any other measure employed in these studies.

\section{Discussion}

To the authors, the most striking features of the studies of male and female homosexuality reported here are $(a)$ the prominent role played by weak and/or hostile fathers in the etiology of homosexuality for both women and men; $(b)$ the lack of a clear role of mothers in female homosexual etiology but the striking role of mothers in the etiology of male homosexuals; $(c)$ the clearer etiological pattern that emerges for male homosexuals; $(d)$ the alienation from mothers, fathers, and "people" that characterized both female and male homosexuals; and (e) the extensive developmental and parent-child relations overlap between the homosexual and heterosexual sample of both sexes.

To us, these data suggest the need for a strong male figure to reinforce feminine role adoption in the developing female child in our culture as it is now constituted. Our findings seem to support Johnson's (1963) theory of sex-role development for females. As our culture is now arranged (or was for this young adult population), the mother as a female model "does not seem to be enough." An "instrumental father figure" also appears to be needed.

The picture for males seems quite clear from the present data and fits surprisingly well with data from two other very different populations (Bieber et al., 1962; Evans, 1969). From all three samples, we have the picture of a modal seductive mother working against maleness in her son, and a weak and/or rejecting and hostile father who discourages modeling on himself and who is also very likely consistently undercut by his wife as his son moves through childhood.

Alienation, lone wolfishness, and a psychology of difference characterize both male and female homosexuals in this sample. This "difference" psychology may also play a part in determining their sex-role adjustmentgiven inadequate models (plus sabotage of the model for the modal male homosexual), do homosexuals simply move sexually in the direction of the most easily perceived similarity -biological similarity-so that the female homosexuals loves other females, the male homosexuals other males? Alienation from their peers may also have cut off influence by models who, for more socially involved children, powerfully reinforce heterosexual identification. Finally, it should be emphasized that there is much overlap in the sample: Many female and male homosexuals come from backgrounds that seem ideally suited for heterosexual development, and vice versa.

\section{REFERENCES}

Apperson, L. B., \& McAdoo, W. G., JR. Parental factors in the childhood of homosexuals. Journal of Abnormal Psychology, 1968, 73, 201-206.

Bieber, I., Dain, H. J., Dince, P. R., Dreli.ich, M. G., Grand, H. G., Gundlaci, R. H., Kremer, M. W., Rifkin, A. H., Wilbur, C. B., \& Bieber, 'T. B. Homosexuality: A psychoanalytical study. New York: Basic Books, 1962.

BENE, E. On the genesis of male homosexuality: An attempt at clarifying the role of the parents. British Journal of Psychiatry, 1965, 111, 803-813.

Bezder, W., \& MAdsen, B. A guide for scoring sex-role identity from a brief version of the Franck Drawing Completion Test. Chicago: University of Chicago, Social Psychology Laboratory, 1970. (Mimeo)

BILLER, H. B. Father absence and the personality development of the male child. Developmental Psychology, 1970, 2, 181-201.

Biller, H. B., \& Borstelmann, L. J. Masculine development: An integrative review. Merrill-Palmer Quarlerly, 1967, 13, 253-294.

Chang, J., \& Block, J. A study of identification in male homosexuals. Journal of Consulting Psychology, 1960, 24, 307-310.

Cottle, T. J., Edward, C. N, \& Pleck, J. The relationship of sex role identity and social and political atitudes. Jonrnal of Personality, 1970, 38, $435-4.52$. 
DIgNAN, M. H. Ego identity and maternal identification. Journal of Personality and Social Psychology, 1965, 1, 476-483.

Evans, R. B. Childhood parental relationships of homosexual men. Journal of Consulting and Clinical Psychology, 1969, 33, 129-135.

Franck, K., \& Rosen, E. A. A projective test of masculinity-femininity. Journal of Consulting Psychology, 1949, 13, 247-256.

Gundlach, R. H., \& Riess, B. F. Self- and sexual identity in the female: A study of female homosexuals. In B. F. Riess (Ed.), New directions in mental health. New York: Grune \& Stratton, 1968.

Heir.brun, A. B., Jr. Sex role, instrumental-expressive behavior, and psychopathology in females. Journal of Abnormal Psychology, 1968, 73, 131-136.

Johnson, M. Sex-role learning in the nuclear family. Child Development, 1963, 34, 319-333.

Kaye, H. E., Berl, S., Clare, J., Eleston, M. R., Gershwin, B. S., Gershwin, P., Kogan, L. S., Torda, C., \& Wilbur, C. B. Homosexuality in women. Archives of General Psychiatry, 1967, 17, $626-634$.
LAzowick, L. M. On the nature of identification. Journal of Abnormal and Social Psychology, 1955, $51,175-183$.

Ltpsitt, P. D., \& Strodtbeck, F. L. Defensiveness in decision making as a function of sex-role identification. Journal of Personality and Social Psychology, $1967,8,10-15$.

McCandisss, B. R. Adolescents: Behavior and development. Hinsdale, Ill.; Dryden Press, 1970.

Miller, D. R., \& Swanson, G. F. Inner conflict and defense. New York: Holt, 1960.

Osgood, C. E., Suci, G. J., \& Tannenbaum, P. H. The measurement of meaning. Urbana: University of Illinois Press, 1957.

Strodtbeck, F. L., Bezdek, W., \& Goldhamer, D. Male sex role and response to a community problem. Sociological Quarterly, 1970, 11, 291-320.

Thompson, N. L., McCandless, B. R., \& Strickland, B. R. Personal adjustment of male and female homosexuals and heterosexuals. Journal of Abnormal Psychology, 1971, 78, 237-240.

(Received September 12, 1972) 